\title{
Social media: An opportunity to reduce hookah smoke during an outbreak of COVID-19
}

\author{
Saeed Bashirian ${ }^{1}$ and Elahe Ezati ${ }^{2 *}$ \\ ${ }^{1}$ Social Determinants of Health Research Center, Hamadan University of Medical Sciences, Hamadan, \\ Iran \\ ${ }^{2}$ Department of Public Health, School of Health, Hamadan University of Medical Sciences, Hamadan, \\ Iran
}

The tobacco epidemic is one of the biggest public health warnings in the world, and 8 million people die every year due to smoking, of which 7 million die due to direct smoking and 2.1 million due to exposure to secondhand smoke [1]. Hookah is a common and traditional way of smoking, which unfortunately has now become a fun and entertaining method, especially among teenagers, in today>s societies, especially in the Middle East. Smoking hookah at an early age and increasing its popularity among adolescents is a concern and an alarm [2].

Changes are taking shape in the behavior and attitudes of today's adolescents, most of which are influenced by the introduction of new communication technology.

It seems that new communication technologies and the growth of new virtual social networks and the possibility of sharing opinions, experiences of millions of active smoking, affect the willingness of adolescents, especially in attracting them to perform some high-risk behaviors, including hookah smoke.

Smoking and coronavirus have similar harmful effects on the body. The use of any tobacco product can cause serious damage to the immune, cardiovascular, and respiratory systems [3]. Moreover, hookah use has acute and long-term detrimental effects on the respiratory and cardiovascular systems and increases the risk of diseases such as coronary artery disease and chronic obstructive pulmonary disease. COVID-19 disease can also cause such damages and problems to the body [3]. In the use of hookah, tobacco is often used through a common path, including the mouth, hose, and chamber, in the hookah structure [4]. Additionally, there is a risk of survival of microorganisms transmitted from consumers in hookah pieces and outfits (including chambers and hoses). On the other hand, most consumers are reluctant to clean hookah after each use because washing and cleaning pieces are very time-consuming [4].

Posting messages on social media about smoking as a global phenomenon, advertising hookah as a social class in various forms and flavors, has become very common today, and these seductive advertisements in the tendency of people to consume Tobacco is effective $[1,3,4]$.

Virtual social networks in interpersonal relationships and in social relationships have the ability to make fundamental changes in the life of each individual. On the other hand, these media have an undeniable role in providing direct and indirect messages and public education; But in order to be highly effective and achieve the intended goal, the transmission of the educational message to the audience must be done scientifically. In 2003, the World Health Organization issued a comprehensive ban on the advertising of tobacco products, and prohibited any activity, whether in traditional media such as television and radio, or through new social media networks such as Instagram, etc., that are directly or indirectly aimed at promoting a tobacco product. So it seems that policymakers and officials need to take approaches to increase control and oversight over the smoking of anti-smoking messages on social media and promote anti-smoking advertisements with negative and harmful consequences of smoking with the aim of countering the normalization of hookah smoke on social media. Evidence also shows that media-based interventions, in addition to facilitating interventions in the formation and 
improvement of healthy behaviors, are effective and costeffective. Given the increasing smoking of social media in developing countries and limited financial resources in these countries; Using social media for health interventions to reduce hookah smoke is a good opportunity $[2,4,5]$.

\section{References}

1. Bashirian S, Barati M, Karami M, Hamzeh B, Ezati E (2020) Predictors of shisha smoking among adolescent females in Western Iran in 2019: Using the Prototype-Willingness Model. Tob Prev Cessat 6: 50 Link: https://bit.ly/3As882e

2. Bashirian S, Barati M, Karami M, Hamzeh B, Ezati E (2020) Effectiveness of E-Learning Program in Preventing WP Smoking in Adolescent Females in West of Iran by Applying Prototype-Willingness Model: A Randomized Controlled Trial. J Res Health Sci 20: e00497. Link: https://bit.ly/3ApHSpb

3. Priyanka Choudhary OP, Singh I, Patra G (2020) Aerosol transmission of SARS-CoV-2: The unresolved paradox. Travel Med Infect Dis 37: 101869. Link: https://bit.ly/2Xsbd3Q

4. Balatsoukas P, Kennedy CM, Buchan I, Powell J, Ainsworth J (2015) The role of social network technologies in online health promotion: a narrative review of theoretical and empirical factors influencing intervention effectiveness. $J$ Med Internet Res 17: e141. Link: https://bit.ly/3EvQ35U

5. Luna S, Pennock MJ (2018) Social media applications and emergency management: A literature review and research agenda. International Journal of Disaster Risk Reduction 28: 565-577. Link: https://bit.ly/2VYI8g6
Discover a bigger Impact and Visibility of your article publication with

\section{Peertechz Publications}

\section{Highlights}

* Signatory publisher of ORCID

* Signatory Publisher of DORA (San Francisco Declaration on Research Assessment)

* Articles archived in worlds' renowned service providers such as Portico, CNKI, AGRIS, TDNet, Base (Bielefeld University Library), CrossRef, Scilit, J-Gate etc.

* Journals indexed in ICMJE, SHERPA/ROMEO, Google Scholar etc.

* OAI-PMH (Open Archives Initiative Protocol for Metadata Harvesting)

* Dedicated Editorial Board for every journal

* Accurate and rapid peer-review process

* Increased citations of published articles through promotions

* Reduced timeline for article publication

Submit your articles and experience a new surge in publication services (https://www.peertechz.com/submission). 